\title{
Abrasive Water Jet Machining Performance on Carbon Epoxy Composite
}

\author{
M. Uthayakumar, S. Vigneshwaran, M. Adam Khan, Adam Slota, S. Jamal Ahmad
}

\begin{abstract}
The main aim of this investigation is to study the abrasive water jet machining performance of the twill weaved carbon fibre reinforced epoxy composite. Abrasive water jet machining experiment was conducted as per L9 orthogonal array, by varying water pressure, transverse speed and SOD. The performance of the composite was analyzed by measuring the material removal rate and kerf. Using Taguchi analysis, the influences of input parameter over the output response was analyzed. It was found that the MRR is highly influenced by the transverse speed whereas kerf is highly influence by the SOD.
\end{abstract}

Keywords : Carbon fiber composite, Abrasive water jet machining, Kerf, Material removal rate.

\section{INTRODUCTION}

Cons omposites are materials comprising of at least two particular constituents. Carbon fibre reinforced polymer composite (CFRP) is solid and light fiber-strengthened plastic which contains carbon filaments. CFRPs can be costly however are normally utilized wherever high strength and unbending nature are required, for example in aviation, car, structural designing, sports products. Abrasive water jet machining is now presently used in various metal cutting process. The Abrasive Water Jet (AWJ) machining parameters such as jet operating water pressure (WP), transverse speed (TS), Standoff Distance (SOD), and concentration of abrasive are important for controlled cutting operation [1]. The quality of machining can be improved by controlling the AWJM parameters [2]. Water jet technology at present increasingly being used in a variety of applications including mining, process, medical and for machining of difficult-to-cut materials like composites, super alloys, rocks and ceramics [3]. In AWJ cutting of Fibre Reinforced Composites (FRCs), the kerf quality and finish produced are usually poor, necessitating finishing operations leading to further delamination [4]. Optimized machining can improve the quality of the cut during AWJM [5]. SOD is the most influencing parameter in affecting the kerf and surface

Revised Manuscript Received on July 22, 2019.

* Correspondence Author

M. Uthayakumar*, Faculty of Mechanical Engineering, Kalasalingam Academy of Research and Education, Srivilliputhur, India. Email: m.uthayakumar@klu.ac.in

S. Vigneshwaran, Faculty of Mechanical Engineering, Kalasalingam Academy of Research and Education, Srivilliputhur, India.

M. Adam Khan, Faculty of Mechanical Engineering, Kalasalingam Academy of Research and Education, Srivilliputhur, India.

Adam Slota, Faculty of Mechanical Engineering, Cracow University of Technology, Krakow, Poland

S. Jamal Ahmad, Faculty of Mechanical Engineering, Khalifa University, UAE. roughness [6]. The present article investigates on mechanism of surface kerf geometry formed and MRR in abrasive water jet machining of carbon epoxy composite. In the present study, four process parameters of abrasive water jet machining namely hydraulic pressure, traverse rate, stand-off distance, and abrasive mass flow rate are considered. Analysis of variance (ANOVA) is performed in-order to investigate the influence of process parameters on MRR, kerf taper ratio, and kerf top width.

\section{MATERIALS AND METHODS}

\section{A. Composite fabrication}

Carbon fibres in mat form was selected as reinforcement. The carbon fiber mat is twill weaved (2/2) with fiber orientation of $0 / 90^{\circ}$. Epoxy LY 556 is the resin which is used as the matrix material. For the present work carbon epoxy composite was fabricated using compression moulding process. The fiber mat was placed over the mild steel mould having size $175 \times 125 \times 10 \mathrm{~mm}$. The selected epoxy resin and hardener were mixed in suitable proportion as recommended by the supplier. The resin mixture is then poured over the reinforcement placed on the mould cavity and rolled by a roller to avoid air traps. Finally, mould was closed with the matching die and compressed at $5 \mathrm{MPa}$ pressure and left to cure for 24 hours at room temperature. Both the mould and matching die was applied with the releasing agent for easy removal of the fabricated composite plate. The fabricated composite plates were shown in Figure 1.

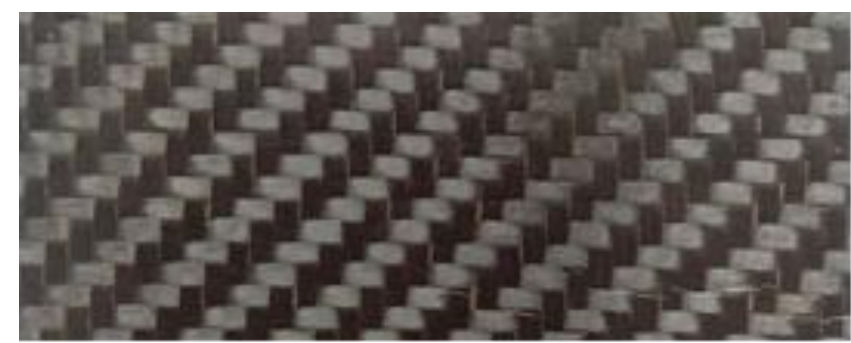

Fig. 1. Fabricated carbon fibre composite

\section{B. Abrasive water jet machining}

The carbon epoxy composites were machined using Abrasive water jet machine DIPS6D-2230 supplied by The Dardi International. The experiment arrangement is shown in Figure 2. The abrasive used in the present experiment was Garnet of size 80 mesh. The mass flow rate of the abrasive particle was maintained constant between 2 to $3 \mathrm{~g} / \mathrm{s}$. 
Using AWJM a straight linear cut of $25 \mathrm{~mm}$ length was made on the hybrid composite by varying the three input parameters water pressure, stand-off distance and transverse speed. For the present experimentation work Taguchi L9 orthogonal array was selected for conducting the experiment. The experiment results were shown in Table 1.

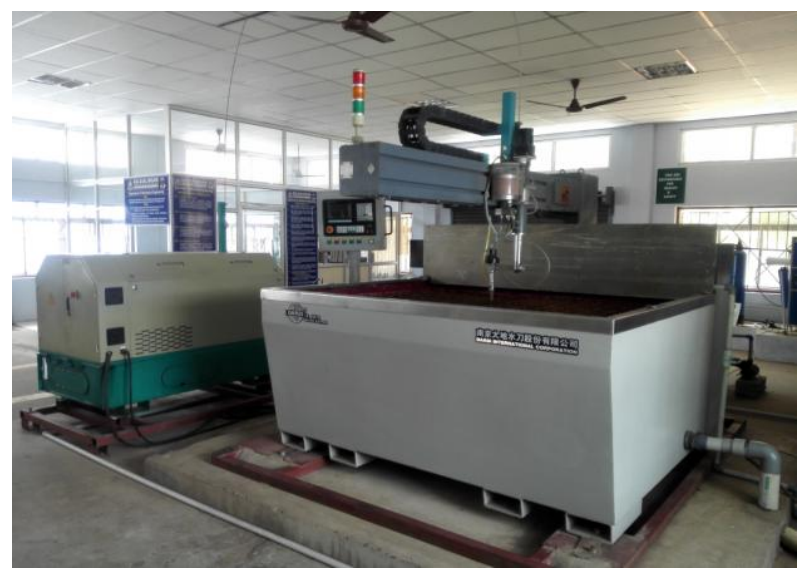

Fig. 2. Abrasive water jet machine

Table- 1: Experiment table and results

\begin{tabular}{|c|c|c|c|c|c|}
\hline $\begin{array}{c}\text { Ex } \\
\mathbf{N o}\end{array}$ & $\begin{array}{c}\text { Water } \\
\text { pressure } \\
(\mathbf{M P a})\end{array}$ & $\begin{array}{c}\text { TS } \\
(\mathbf{m m} / \mathbf{m i n})\end{array}$ & $\begin{array}{c}\text { SOD } \\
(\mathbf{m m})\end{array}$ & $\begin{array}{c}\text { KT } \\
(\mathbf{d e g r e e})\end{array}$ & $\begin{array}{c}\mathbf{M R R} \\
\left(\mathbf{m m}^{\mathbf{3}} / \mathbf{m i n}\right)\end{array}$ \\
\hline 1 & 168 & 5 & 1 & 0.680 & 7.17 \\
\hline 2 & 168 & 15 & 2 & 0.924 & 18.54 \\
\hline 3 & 168 & 25 & 3 & 1.014 & 30.29 \\
\hline 4 & 216 & 5 & 2 & 0.741 & 7.90 \\
\hline 5 & 216 & 15 & 3 & 0.958 & 21.80 \\
\hline 6 & 216 & 25 & 1 & 0.726 & 26.49 \\
\hline 7 & 264 & 5 & 3 & 0.807 & 10.78 \\
\hline 8 & 264 & 15 & 1 & 0.674 & 16.40 \\
\hline 9 & 264 & 25 & 2 & 0.849 & 30.55 \\
\hline
\end{tabular}

The kerf width was measured using the optical microscope having magnification of $1000 \mathrm{X}$ and the top and bottom kerf measurements. The kerf measurement was done at $100 \mathrm{X}$ magnification. With the use of Kerf values measured at top and bottom surface, the machining quality was computed by finding material removal rate (MRR) and kerf taper (KT) using equations $1 \& 2$.

$\mathrm{MRR}=\mathrm{t} \times((\mathrm{W} 1+\mathrm{W} 2) / 2) \times$ transverse speed

$\operatorname{Kerf}$ taper $(\mathrm{KT})=((\mathrm{W} 1-\mathrm{W} 2) \times 180 / 2 \pi \mathrm{t})$

Where, W1 is the top kerf width, W2 is the bottom kerf width and $t$ is the thickness of the cut or depth of cut.

\section{RESULT AND DISCUSSION}

\section{A. Analysis of Material Removal Rate (MRR)}

The effect of AWJM variables on the MRR is shown in Figure 3 and 4. This is also evident from the ANOVA results shown in Table 2. The ANOVA analysis shows the significance of the three parameters affecting the MRR. F-value of water pressure, Transverse speed and SOD are $0.14,143.09$ and 6.23 respectively and their corresponding $\mathrm{p}$-values for all the parameters is $0.879,0.007$, and 0.138 . It is noted that the Transverse Speed contributed $95.11 \%$ in affecting the MRR followed by the SOD (4.14\%) and Water Pressure $(0.09 \%)$. The material removal rate was highly influenced by the transverse speed. At high TS the nozzle moves more rapidly and removes more surface material because of the scattering of the abrasive particles.

Table 2. ANOVA table for MRR

\begin{tabular}{|l|l|l|l|l|l|l|l|}
\hline Source & DF & Seq SS & Contribution & Adj SS & $\begin{array}{l}\text { Adj } \\
\text { MS }\end{array}$ & F-Value & P-Value \\
\hline WP & 2 & 0.605 & $0.09 \%$ & 0.605 & 0.303 & 0.14 & 0.879 \\
\hline TS & 2 & 629.85 & $95.11 \%$ & 629.85 & 314.92 & 143.09 & 0.007 \\
\hline SOD & 2 & 27.408 & $4.14 \%$ & 27.40 & 13.70 & 6.23 & 0.138 \\
\hline Error & 2 & 4.402 & $0.66 \%$ & 4.402 & 2.201 & & \\
\hline Total & 8 & 662.27 & $100.00 \%$ & & & & \\
\hline
\end{tabular}

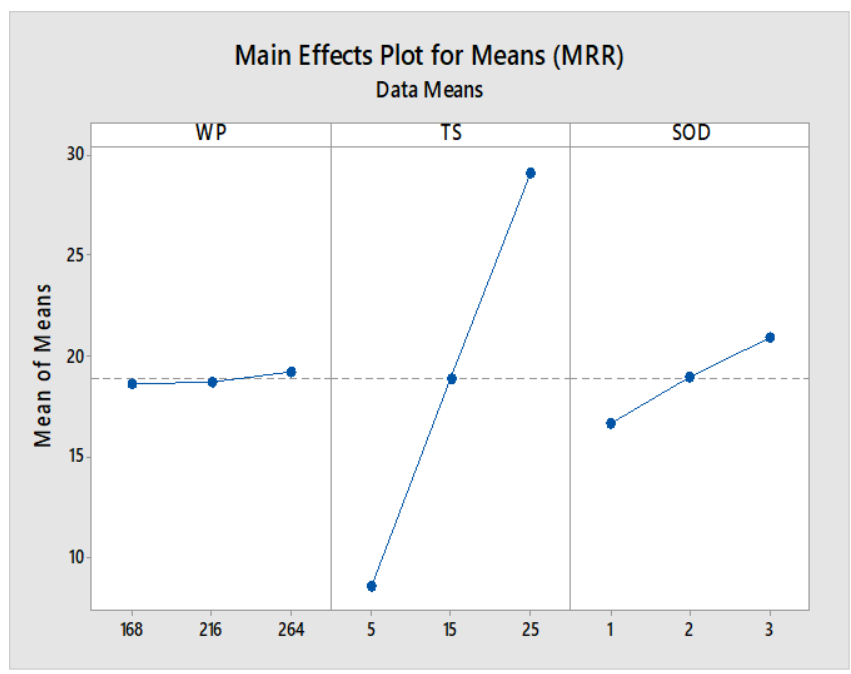

Fig. 3. Main effect plot for means (MRR)

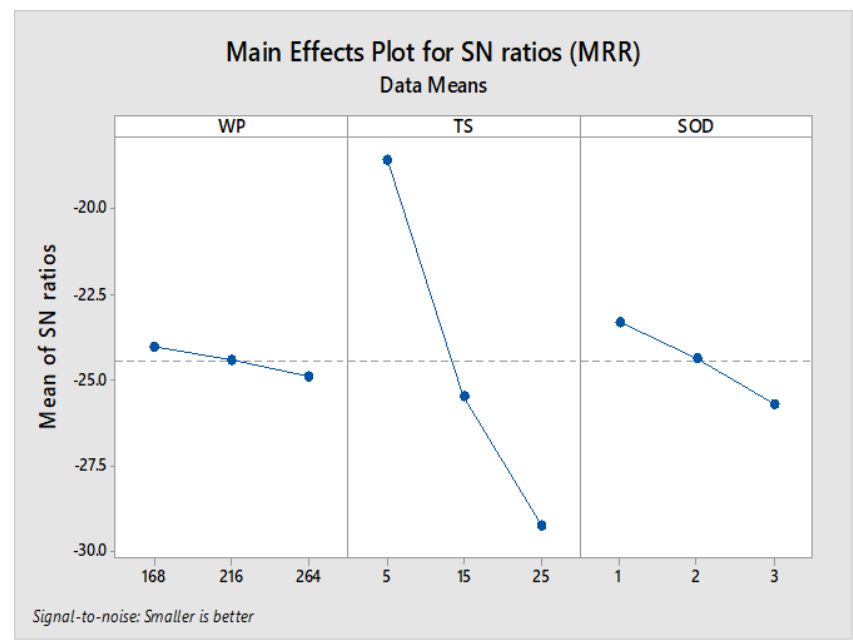

Fig. 4. Main effect plot for $\mathrm{SN}$ ratio (MRR)

\section{B. Analysis of Kerf (KT)}

The effect of AWJM variables on the KT is shown in Figure 5 and 6 . This is also evident from the ANOVA results shown in Table 3. The ANOVA analysis shows the significance of the three parameters affecting the KT. F-value of water pressure, Transverse speed and SOD are 25.26, 46.65 and 146.42 respectively and their corresponding $\mathrm{p}$-values for all the parameters is 
$0.038,0.021$, and 0.007 . It is noted that the SOD contributed $66.76 \%$ in affecting the KT followed by the Transverse Speed $(21.27 \%)$ and Water Pressure $(11.52 \%)$. SOD is the main factor for the increase in kerf. Higher the SOD increases the kerf. The main reason is because of the divergence of water jet at high pressure.

Table- 3: ANOVA table for Kerf

\begin{tabular}{|l|l|l|l|l|l|l|c|}
\hline $\begin{array}{c}\text { Sourc } \\
\text { e }\end{array}$ & DF & $\begin{array}{c}\text { Seq } \\
\text { SS }\end{array}$ & Contribution & Adj SS & Adj MS & F Value & $\begin{array}{c}\text { V } \\
\text { Value }\end{array}$ \\
\hline WP & 2 & 0.014 & $11.52 \%$ & 0.014 & 0.007 & 25.26 & 0.038 \\
\hline TS & 2 & 0.026 & $21.27 \%$ & 0.026 & 0.013 & 46.65 & 0.021 \\
\hline SOD & 2 & 0.083 & $66.76 \%$ & 0.083 & 0.041 & 146.42 & 0.007 \\
\hline Error & 2 & 0.0005 & $0.46 \%$ & 0.0005 & 0.0002 & & \\
\hline Total & 8 & 0.124 & $100.00 \%$ & & & & \\
\hline
\end{tabular}

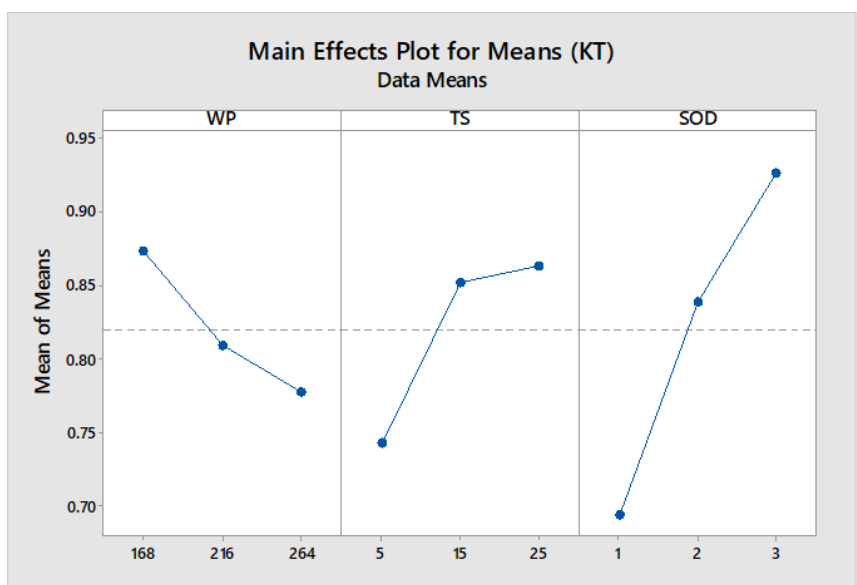

Fig. 5. Main effect plot for means (KT)

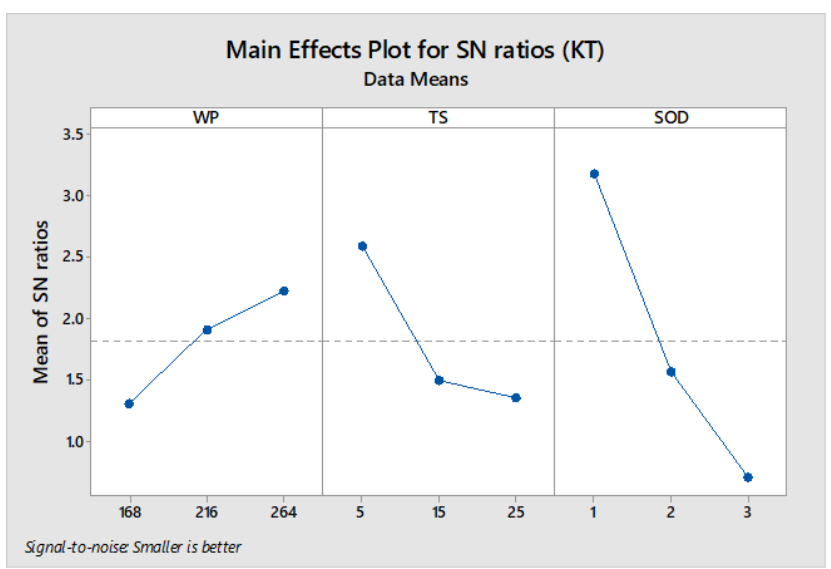

Fig. 6. Main effect plot for $\mathrm{SN}$ ratio (KT)

\section{CONCLUSION}

Carbon fibre reinforced polyester composites were fabricated successfully. From the investigation of the fabricated composites the following results were concluded. Transverse Speed contributed $95.11 \%$ in affecting the MRR followed by the SOD (4.14\%) and Water Pressure (0.09\%). The material removal rate was highly influenced by the transverse speed. At high TS the nozzle moves more rapidly and removes more surface material because of the scattering of the abrasive particles. SOD $((21.27 \%))$ is the main factor influencing the kerf. Higher the SOD increases the kerf because of the divergence of water jet at high pressure. Next to SOD, Transverse Speed contributed $21.27 \%$ and Water Pressure contributed $11.52 \%$ in affecting the kerf.

\section{REFERENCES}

1. Dhanawade, Ajit, and Shailendra Kumar, "Experimental study of delamination and kerf geometry of carbon epoxy composite machined by abrasive water jet," Journal of Composite Materials, vol.51. pp. 3373-3390, 2017

2. D. Doreswamy, D. Anjaiah, and N. Yagnesh, "An investigation of abrasive water jet machining on graphite/glass/epoxy composite," International Journal of Manufacturing Engineering, vol. 2015, pp. 11, 2015.

3. M. Haddad, R. Zitoune, F. Eyma and B. Castanié. "Influence of machining process and machining induced surface roughness on mechanical properties of continuous fiber composites," Experimental Mechanics, vol.55, pp.519-528, 2015.

4. Siddiqui, T. Uddin, M. Shukla, and Pankaj B. Tambe, "Comparative investigation of abrasive waterjet cut kerf quality characteristics for aramid, glass and carbon fiber reinforced composites used in transport aircraft applications," Proceedings of the 2009 American WJTA Conference, Houston, Texas. 2009.

5. Bhowmik, Sumit, and Amitava Ray. "Prediction and optimization of process parameters of green composites in AWJM process using response surface methodology," The International Journal of Advanced Manufacturing Technology, vol.87, pp.1359-1370, 2016.

6. V.Arumugaprabu, S. Thirumalai, and M. Uthayakumar, "Performance evaluation of abrasive water jet machining on banana fiber reinforced polyester composite." Journal of natural fibers, vol.14, pp.450-457, 2017.

\section{AUTHORS PROFILE}

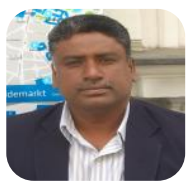

Dr. M. Uthayakumar has obtained Master of Engineering in Production Engineering from Thiagarajar College of Engineering (Autonomous), Madurai, India and Doctorate from Department of Production Engineering, National Institute of Technology, Tiruchirappalli. He has published 145 papers in the international journals and conference. Currently he is a Professor at Department of Mechanical Engineering, Kalasalingam Academy of Research and Education, Krishnankoil, Virudhunagar Dist.

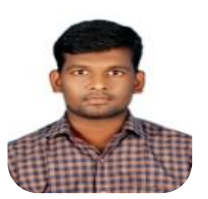

Mr. Vigneshwaran is a research scholar at Kalasalingam Academy of Research and Education, India. His area of interest includes polymer composites, composite machining and tribology.

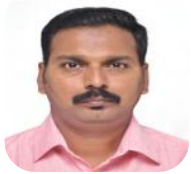

Dr. M. Adam Khan is a Post-Doctoral Researcher from the Department of Mechanical and Industrial Engineering Technology, University of Johannesburg, South Africa. He received his Doctoral Degree from National Institute of Technology, Tiruchirappalli, India. His Bachelor (B.E.) and Master Degree (M.E.) from Anna University, Chennai in the specialization of Production and Design. His research focused on surface engineering and metallurgical analysis on processed materials. $\mathrm{He}$ has published 38 technical articles in different journals of international repute. 